\title{
Chondrogenic differentiation of bovine bone marrow mesenchymal stem cells in pellet cultural system
}

\author{
Darko Bosnakovski ${ }^{a}$, Morimichi Mizuno ${ }^{b}$, Gonhyung Kimª ${ }^{\mathrm{a}}$ Taketo Ishiguro ${ }^{\mathrm{a}}$, \\ Masahiro Okumura $^{\mathrm{a}}$, Toshihiko Iwanaga ${ }^{\mathrm{c}}$, Tsuyoshi Kadosawa ${ }^{\mathrm{a}}$, and Toru Fujinaga ${ }^{\mathrm{a}}$ \\ ${ }^{a}$ Laboratory of Veterinary Surgery, Department of Clinical Science, Graduate \\ School of Veterinary Medicine; ${ }^{\mathrm{b}}$ Graduate School of Dentistry, Department of Oral Health Science; \\ ${ }^{\mathrm{c}}$ Graduate School of Medicine, Department of Cytology and Histology, Hokkaido University, Sapporo, Japan
}

(Received 15 September 2003; revised 17 February 2004; accepted 18 February 2004)

\begin{abstract}
Objective. Pluripotent mesenchymal stem cells (MSC) have been isolated and well characterized from several tissue sources, including bone marrow stroma. MSC from different animals showed slight differences in morphology and in the potential to differentiate. In the present study, we isolated MSC from bovine bone marrow and induced chondrogenesis in order to establish a new experimental model of stem cell research.

Methods. Bone marrow was harvested from 8 calves. For inducing chondrogenesis, MSC were cultured in pellet culture system in a chemically defined medium supplemented with 0 and $10 \mathrm{ng} / \mathrm{mL}$ of transforming growth factor $\beta 1$ (TGF- $\beta 1$ ). Chondrogenic differentiation was evaluated by histological, immunohistochemical, and in situ hybridization techniques. The degrees of genes expression were measured by quantitative RT-PCR.

Results. Metachromatic alcian blue staining and immunoreactivity for type II collagen were detected in both pellet groups ( 0 and $10 \mathrm{ng} / \mathrm{mL}$ TGF- $\beta 1)$ after 7 days of culturing. In situ hybridization demonstrated strong expression of type II collagen and aggrecan mRNAs in the round cells located at the center region of pellets and at densely organized areas. On the other hand, type I collagen mRNA was strongly expressed in the superficial layer of the pellets. After 20 days of pellet culture, expression of type II collagen mRNA in the cells which were not treated by TGF- $\beta 1$ was 1.7-fold higher compared with that treated by TGF- $\beta 1$.

Conclusion. Independent, spontaneous chondrogenesis of bovine MSC in pellet culture occurred without addition of any external bioactive stimulators, namely factors from TGF$\beta$ family, which were previously considered necessary. (c) 2004 International Society for Experimental Hematology. Published by Elsevier Inc.
\end{abstract}

Adult stem cells have been isolated and well characterized from several tissue sources including bone marrow [1], central nervous system [2,3], retina [4], skeletal muscles [5], dermis of mammalian skin [6], and adipose tissue [7]. In the past three decades, most of the work was focused on mesenchymal stem cells (MSC) found within the bone marrow stroma. Bone marrow MSC were purified and expanded and multilinage differentiation was induced in a number of species including rat [8], rabbit [9], dog [10],

Offprint requests to: Darko Bosnakovski, D.V.M., Laboratory of Veterinary Surgery, Department of Veterinary Clinical Science, Graduate School of Veterinary Medicine, Hokkaido University, 060-0818, Sapporo, Japan; E-mail: darko@vetmed.hokudai.ac.jp human [1,11], horse [12], pig [13], and cat [14]. For inducing differentiation, MSC should be cultivated under appropriate culture conditions and stimulated with some bioactive factors. Many growth factors, including transforming growth factor $\beta 1$ (TGF- $\beta 1$ ), bone morphogenic protein (BMP), fibroblast growth factor (FGF), and insulin-like growth factor (IGF-I), have been evaluated for the potential to enhance chondrogenesis [15].

Defects of the cartilage have been known to be poor healing injuries, which treated by conventional surgical methods do not lead to hyaline cartilage regeneration. For this purpose, transplantation of allogeneic or autologous pluripotentional or mature-differentiated cells that are expanded ex vivo have been attempted to cure such defects. 
Transplantation of autologous chondrocytes is limited by lack of suitable donor sites from where large cartilage samples could be harvested, and by limited potential of mature chondrocytes to be expanded in vitro without losing their phenotype [16]. These disadvantages can be substituted by application of the bone marrow MSC in repairing articular cartilage defects. Experimental results, in which rabbit model was used, have been shown that autologous bone marrow MSC transplanted into artificial osteochondral defects were able to differentiate into chondrocytes and repair the defects with hyaline cartilage [9].

Bone marrow MSC harvested from different species displayed slight differences in morphology and differentiation potential. The number of MSC found in canine bone marrow is fourfold higher than in humans. Canine MSC have a much faster doubling time, but lose the osteogenic potential after second passage [10]. Furthermore, canine MCS did not form calcificated nodules during osteogenesis in vitro, which was observed in human and rat MSC [10]. During osteogenesis induced by dexamethasone, feline bone marrow MSC did not express alkaline phosphatase (ALP) [14], or human MSC did not express osteocalcin mRNA [17]. Dexamethasone is a potent inducer of osteocalcin and ALP, which have been reported to be typical markers of osteogenic differentiation in other species $[10,13,16]$. MSC harvested from commonly used strains of inbred mice displayed variations in yield, growth, and differentiation [18]. Considering those and other findings, it could be concluded that differentiation processes and mechanisms that are valid for MSC from one species are not necessarily valid for others. Besides species character, bone marrow donor, isolation method, in vitro cell expansion technique, media formulation, and other factors also must be considered in experiments with MSC [19-21].

The majority of research concerning MSC has been done on rodents or humans. Small experimental animals can be used to research the principles of stem cell transplantation therapy, but prior to transferring this technology to the therapy it is important to introduce it to a large-animal model, which is biomechanically more relevant to humans [10,22-24]. Cattle are considered large-animal experimental models, and as such give numerous advantages for making progress in clinical application of MSC to human medicine, especially in musculoskeletal health problems. The bovine animal model, which we introduced for the first time in the stem cell research, is a potential donor of relatively large amounts of bone marrow aspirate, and consequently leads to sufficient yield of isolated MSC, providing further opportunity to use it in numerous in vitro and in vivo experiments.

The objective of this study is to evaluate suitable methods for bovine MSC isolation, in vitro expansion, and chondrogenic differentiation, and to facilitate further in vitro studies and in vivo experiments for resurfacing cartilage defects using the bovine model.

\section{Materials and methods}

\section{Materials}

All reagents and supplements were purchased from Sigma Chemical Co. (St. Louis, MO, USA) unless otherwise noted.

\section{Harvest and isolation of bovine MSC and chondrocytes}

Bone marrow was obtained from tuber coxae, femur, crista tibia, and proximal end of the humerus of 8 Holstein Friesian calves, ranging from 2 days to 6 months old. The marrow was drawn into $25-\mathrm{mL}$ syringes containing 1000 units of heparin following aseptical preparation of the harvesting fields and infiltration with local anesthetic.

Bovine MSC were isolated by modification of methods previously described $[15,16,25,26]$. Briefly, one volume of bone marrow sample was mixed with two volumes of phosphate-buffered saline (PBS), and the mixture was centrifuged at $300 \mathrm{~g}$ for 10 minutes. The supernatant was discarded, and the pellet was washed two more times with Dulbecco's Modified Eagle Medium (DMEM; GIBCO BRL, Grand Island, NY, USA). After determination of the cell viability and the number using trypan blue staining, following lysis of erythrocytes by the addition of $4 \%$ acetic acid, $5 \times 10^{4} /$ $\mathrm{cm}^{2}$ nucleated cells were plated in T-75 culture flasks in DMEM (low glucose) containing: penicillin G $100 \mathrm{U} / \mathrm{mL}$, streptomycin $100 \mu \mathrm{g} / \mathrm{mL}$, amphotericin B $0.25 \mu \mathrm{g} / \mathrm{mL}$, HEPES $2.4 \mathrm{mg} / \mathrm{mL}$, $\mathrm{NaHCO}_{3} 3.7 \mathrm{mg} / \mathrm{mL}$, and $10 \%$ fetal bovine serum (FBS; lot No. 5300C, ICN Biomedicals, Aurora, OH, USA). The cells were incubated at $37^{\circ} \mathrm{C}$ in a humidified atmosphere containing $5 \% \mathrm{CO}_{2}$. After 4 days of culturing, the nonadherent cells were removed by changing the culture media. Following the initial 4 days, which were necessary for cells to attach to the flask, medium was changed every 2 to 3 days. On days 12 to 13 , cells were detached $(0.25 \%$ trypsin/ $0.1 \%$ EDTA) and replated according to the standard cultural technique at a $1: 3$ or 1:4 dilution (first passage). When cells began to reach near confluent stage, they were trypsinized and used for the preparation of pellets. Cell cultures from each calf were maintained separately.

Chondrocytes were isolated from the articular cartilage harvested from the same calf, from which bone marrow was aspirated. Briefly, cartilage pieces were digested with $0.1 \mathrm{mg} / \mathrm{mL}$ of collagenase (Wako Pure Chemical, Osaka, Japan) in DMEM/10\% FBS for 18 hours at $37^{\circ} \mathrm{C}$ with gentle stirring followed by filtering through a $100-\mu \mathrm{m}$ nylon mesh. Isolated primary chondrocytes were cultured in monolayer manner under same conditions as MSC for 20 days and were used for positive control $[27,28]$.

\section{Pellet culture}

Cells from the first passage were resuspended in the serum-free chemically defined medium consisting of DMEM (high-glucose), insulin $6.25 \mu \mathrm{g} / \mathrm{mL}$, transferin $6.25 \mu \mathrm{g} / \mathrm{mL}$, selenious acid $6.25 \mu \mathrm{g} /$ $\mathrm{mL}$, bovine serum albumin $1.25 \mathrm{mg} / \mathrm{mL}$, pyruvate $1 \mathrm{mM}$, linoleic acid $5.35 \mu \mathrm{g} / \mathrm{mL}$, and ascorbate 2 -phosphate $50 \mu \mathrm{g} / \mathrm{mL}$. For preparation of each pellet, aliquots of $1 \times 10^{6}$ cells in $1 \mathrm{~mL}$ of defined medium were spun down at $500 \mathrm{~g}$ for 10 minutes in a $15-\mathrm{mL}$ polypropylene conical tube [29]. Pellets were divided into 2 experimental groups according to the presence of the TGF- $\beta 1$ ( 0 and 10 $\mathrm{ng} / \mathrm{mL}$ ) (R\&D Systems, Minneapolis, MN, USA) in the medium, and cultivated at $37^{\circ} \mathrm{C}$ in a humidified atmosphere including $5 \%$ $\mathrm{CO}_{2}$ for 20 days by changing the medium every 2 days. 
Histological and immunohistochemical analysis of the pellet Pellets were harvested after 7, 10, and 20 days of culturing, fixed in $10 \%$ buffered formalin for 2 hours, embedded in $2 \%$ agarose for easy manipulation, and kept in $70 \%$ ethanol overnight. Samples were embedded in paraffin and $5-\mu \mathrm{m}$ sections were cut. Hematoxylin and Eosin (H\&E) staining of paraffin sections was done for evaluation of cell morphology in pellets. Sulfated glicosaminoglicans (GAG) were visualized by staining with $0.5 \%$ alcian blue for 10 minutes. Collagen type I and II were detected using polyclonal antibodies (LSL Co., Tokyo, Japan) as previously described [27]. Briefly, after deparaffinization, sections were predigested with tryp$\sin$ at $37^{\circ} \mathrm{C}$ for 30 minutes to facilitate antibody access, endogenous peroxidase was quenched by the treatment of $0.3 \% \mathrm{H}_{2} \mathrm{O}_{2}$ in methanol at room temperature for 30 minutes, and nonspecific antibody binding was blocked by incubation of sections in a $10 \%$ normal goat serum at $37^{\circ} \mathrm{C}$ for 30 minutes. Rabbit anti-bovine collagen type I and II diluted 1:500 and 1:1000 respectively in 0.01 M PBS (pH: 7.4) were applied as a primary antibody at $4^{\circ} \mathrm{C}$, overnight. Sections were then incubated with the secondary antibody, swine anti-rabbit immunoglobulin (DAKO, Glostrup, Denmark), for 60 minutes followed by rabbit PAP kit (DAKO). Collagen type I and II were visualized by the reactions with $0.05 \%$ diaminobenzidine containing $0.01 \% \mathrm{H}_{2} \mathrm{O}_{2}$.

\section{In situ hybridization}

For in situ hybridization, pellets were embedded in OCT compound and frozen in liquid nitrogen. Frozen sections $(10 \mu \mathrm{m})$ were cut and mounted on silane-coated glass slides. Two kinds of nonoverlapping 45-mer antisense oligonucleotide probes were synthesized to detect every mRNA of interest. The following gene sequences were used: for collagen type I nucleotide residues 2408-2453 and 4108-4153 (Gen Bank AB008683); collagen type II nucleotide residues 278-323 and 777-822 (Gen Bank X02420); and aggrecan nucleotide residues 5540-5585 and 6750-6795 (Gen Bank U76615). In situ hybridization was performed as previously described [30]. Briefly, the oligonucleotides were labeled with ${ }^{35} \mathrm{~S}$ adenosine thiotriphosphate to a specific activity of $0.5 \times 10^{9} \mathrm{dpm} /$ $\mu \mathrm{g}$ DNA, using terminal deoxynucleotidyl transferase. Sections were fixed with $4 \%$ paraformaldehyde in $0.1 \mathrm{M} \mathrm{PBS} \mathrm{(pH} \mathrm{7.4)} \mathrm{for}$ 15 minutes and acetylated with $0.25 \%$ acetic anhydride in $0.1 \mathrm{M}$ triethanolamine- $\mathrm{HCl}(\mathrm{pH}$ 8.0) for 10 minutes. Hybridization was performed at $42^{\circ} \mathrm{C}$ overnight by the reaction with labeled oligonucleotide probes at a final radioactivity of $0.5 \times 10^{7} \mathrm{cpm} / \mathrm{mL}$ in $50 \%$ formamide, which contained $30 \mathrm{mM}$ Tris- $\mathrm{HCl}(\mathrm{pH} 7.4), 0.6 \mathrm{M}$ $\mathrm{NaCl}, 1 \mathrm{mM}$ EDTA, $100 \mathrm{mM}$ dithiothreitol, $1 \times$ Denhardt's solution, $0.25 \%$ sodium dodecyl sulfate (SDS), $10 \%$ dextran sulfate, and $200 \mu \mathrm{g} / \mathrm{mL}$ yeast tRNA. Control hybridization was performed in the presence of 20-fold excess amount of unlabeled antisense probe. Slides were washed in $2 \times$ SSC containing $0.1 \%$ sarkosyl for 30 minutes at room temperature, followed by washing 2 times in $0.1 \times$ $\mathrm{SSC} / 0.1 \%$ sarkosyl for 40 minutes at $55^{\circ} \mathrm{C}$. Slides were dipped into autoradiographic emulsion (NTB-2, Kodak, Rochester, NY, USA), exposed at $4^{\circ} \mathrm{C}$ for 4 weeks, and counterstained with hematoxylin.

\section{Measurement of mRNA level by quantitative PCR method} Expressions of mRNA for genes of interest in the MSC cultured in pellet culture for 1 and 20 days, and in MSC and chondrocytes cultured in monolayer for 20 days, were measured by quantitative PCR method. Total RNA was isolated using Trizol (Invitrogen,
Life Technologies, Carlsbad, CA, USA) following the manufacturer's instruction. After samples were treated by DNase to remove possible contamination of genomic DNA, first-strand complementary DNA (cDNA) was synthesized from $1 \mu \mathrm{g}$ total RNA using M-MLV reverse transcriptase (Invitrogen) with oligo $(\mathrm{dT})_{20}$ used as a primer in a $20-\mu \mathrm{L}$ reaction mixture. The amount of cDNA was measured by quantitative PCR method using Smart Cycler System (Cepheid, Sunnyvale, CA, USA). The PCR reaction was carried out in a $25-\mu \mathrm{L}$ final volume, which contained PCR buffer, $3 \mathrm{mM} \mathrm{MgCl}_{2}, 0.3 \mathrm{mM}$ dNTP mixture, $0.3 \mu \mathrm{M}$ of each primer, and Taq polymerase (1.25 units/tube) (Takara Biomedicals, Otsu, Japan). The primer sequences specific for bovine glyceraldehyde3-phosphate dehydrogenase (GAPDH), aggrecan, and collagen type I and II (Table 1) genes were obtained from Gen Bank and were synthesized at System Science (Sapporo, Japan). Thermal cycling was carried out at $95^{\circ} \mathrm{C}$ for 5 seconds, $60^{\circ} \mathrm{C}$ for 15 seconds, and $75^{\circ} \mathrm{C}$ for 15 seconds. The amount of PCR product was estimated by measurement of the intensity of fluorescence of SYBR Green I interacted into the PCR product. The mRNA expression level of target genes was normalized by dividing with the mRNA level of GAPDH. Quality of the PCR products was checked by melting curve analysis and electrophoresis of the PCR product. In addition, the identity of each PCR product was confirmed by sequence analysis (ABI-PRISM 310 Genetic Analyzer, PE Biosystems, Foster City, CA, USA).

\section{Results}

\section{Cell culture}

Spindle bipolar to polygonal fibroblastic cells attached to the flask were observed after 4 days of culturing, at the first changing of the medium (Fig. 1A). After 10 to 13 days, the cell culture reached confluence and, at the places where cells overlap, exhibited more cuboidal morphology. Cells in the first or further passages showed uniform monolayer (Fig. 1C) and needed approximately 1 week to reach confluence.

Table 1. Chondrogenic marker genes used in quantitative PCR (Q-PCR)

\begin{tabular}{llcc}
\hline Gene & Primer nucleotide sequence & $\begin{array}{c}\text { Product } \\
\text { size (bp) }\end{array}$ & $\begin{array}{c}\text { Accession } \\
\text { number }\end{array}$ \\
\hline GAPDH & $\begin{array}{c}\text { Forward 5' CCT TCA TTG ACC } \\
\text { TTC ACT ACA TGG TCT A }\end{array}$ & 127 & U85042 \\
& Reverse 5' TGG AAG ATG GTG & & \\
ATG GCC TTT CCA TTG & & \\
Collagen I & Forward 5' TGC TGG CCA & 120 & AB008683 \\
& ACC ATG CCT CT & & \\
& Reverse 5' CGA CAT CAT & & \\
Collagen II & Forward 5' ATC CTT GCA G & & \\
& AAA CCC AAA GG & 147 & X02420 \\
& Reverse 5' CCA GTT CAG & & \\
GTC TCT TAG AG & & \\
Aggrecan & Forward 5' CAC TGT TAC & 303 & U76615 \\
& CGC CAC TTC CC & & \\
& Reverse 5' GAC ATC GTT & & \\
& CCA CTC GCC CT & & \\
\hline
\end{tabular}



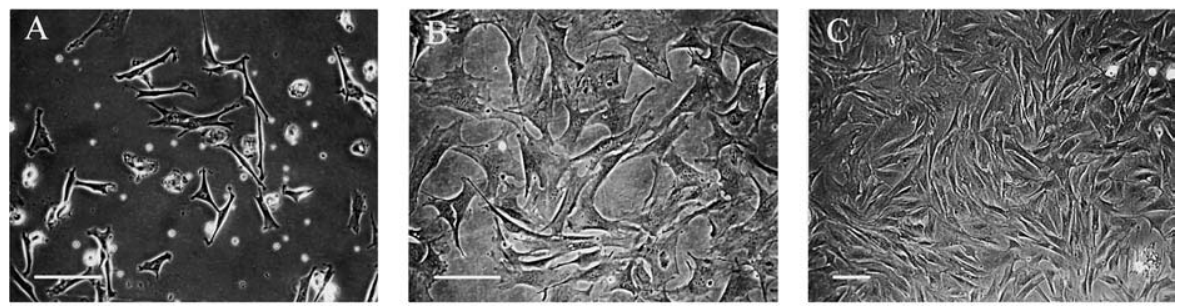

Figure 1. Morphology of bovine mesenchymal stem cells (MSC) cultured in monolayer manner on day 4 (A) and day 10 (B) in primary culture, and on day 7 (C) in first passage analyzed by phase-contrast microscope. Spindle bipolar to polygonal fibroblastic cells could be noticed after 4 days of culturing. Scale bar $100 \mu \mathrm{m}$.

In our experiment, cells from the first passage were used for pellet preparation. After centrifuging, a single compact pellet was formed within 1 to 2 days of incubation in a chemically defined medium. Approximately $85 \%$ of total prepared samples formed clearly identifiable pellets, which were further used in the experiment. The reason for unsuccessful pellet formation of some prepared samples might be unequal quality of isolated cells from different aspirations. Large differences of cell yield number and quality of MSC in aspirates from the same donor at the same time were previously reported, as some cell lines lose potential for differentiation with time, even under standard culture conditions [21,31].

\section{Histology and immunohistochemistry}

For histological and immunohistochemical evaluation, pellets were harvested after 7, 10, and 20 days of culturing. Pellets were divided into 2 experimental groups, according to the presence of TGF- $\beta 1$ ( 0 and $10 \mathrm{ng} / \mathrm{mL})$ in the culturing medium. On examination of paraffin sections stained with $\mathrm{H} \& \mathrm{E}$, no notable differences in morphology of both pellet groups after the same period of culturing (Figs. 2 and 3) were detected. On day 10 , the periphery of the pellet consisted of elongated cells arranged in a few layers, while the center region contained plump, rounded cells (Fig. 2E). On day 20 , pellets retained the previous structure, except that much more extracellular matrix was observed surrounding the cells in the center of the pellets. Metachromatic staining with alcian blue, indicative for matrix of cartilage, was detected in all of the groups of pellets on day 7, 10, and 20. Staining was stronger in the center of the pellets on day 7 , but this difference decreased over time of culturing. On day 7 in the center of the pellet, there were cells in lacunae with the appearance of hypertrophic chondrocytes surrounded by metachromatic stained matrix. This morphological modification of the cells was time dependent, and on day 20 all of the cells in the pellet had chondrogenic appearance, except
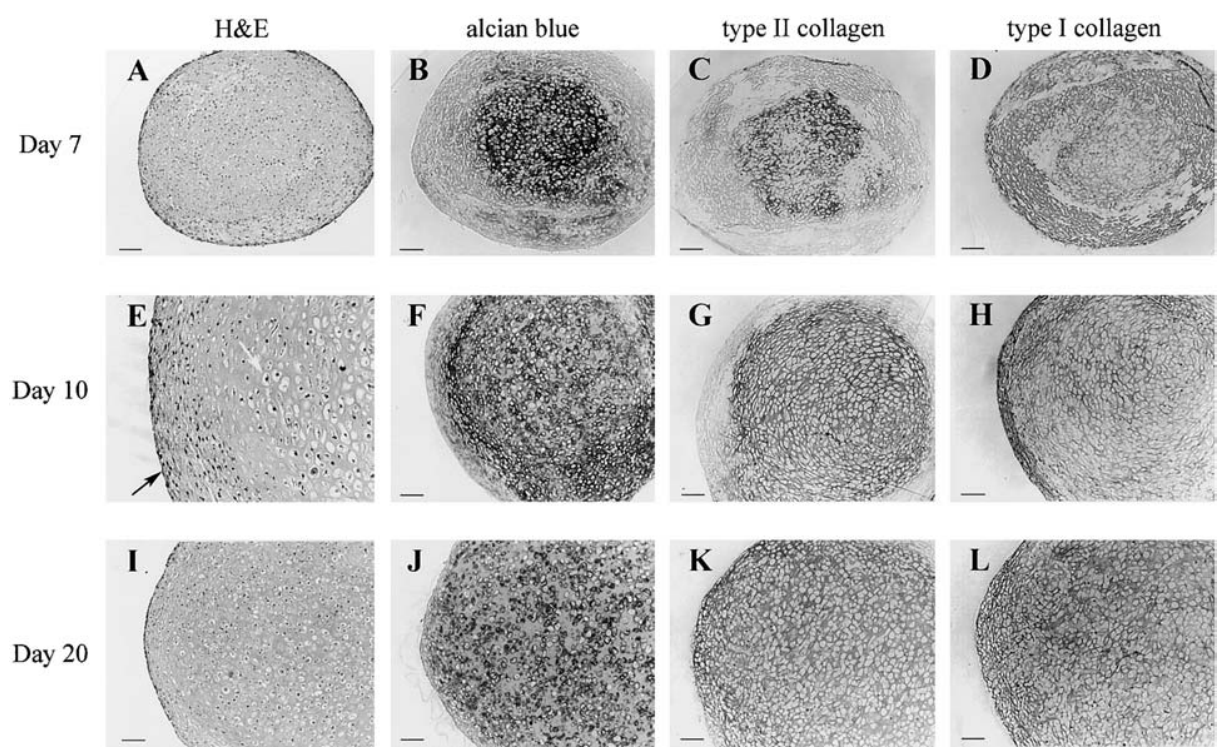

Figure 2. MSC cultured in pellet culture system on day 7 (A-D), on day 10 (E-H), and on day 20 (I-L) without treatment by TGF- $\beta 1$. Hematoxylin and eosin staining (H\&E) of the pellets (A, E, I); alcian blue staining (B, F, J); immunohistochemical staining for detection of type II collagen $(\mathbf{C}, \mathbf{G}, \mathbf{K})$ and type I collagen (D, H, L). Positive metachromatic staining and immunoreactivity for type II collagen was detected on day 7 in the center of the pellet, which increased towards the surface of the pellet time depending. Stronger expression of type I collagen was detected on the surface and in the periphery layers of the pellet. On day 10 , cells that showed appearance of hypertrophic chondrocytes were clearly identified in the center (white arrow), and elongated cells in the periphery layers (black arrow) of the pellets. Scale bar $100 \mu \mathrm{m}$. 

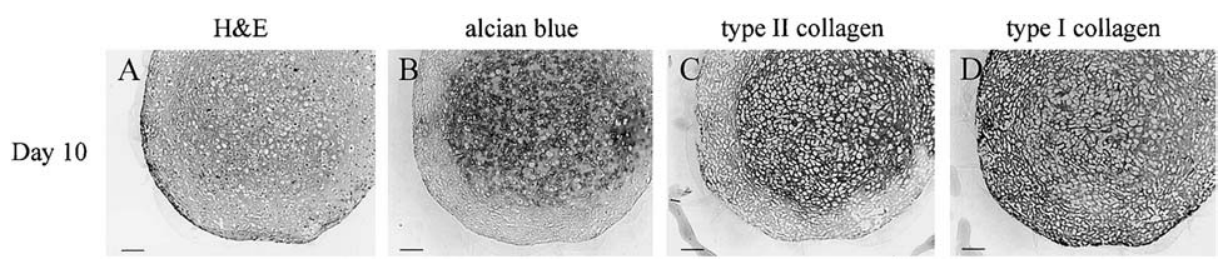

Figure 3. MSC cultured in pellet culture system on day 10 treated by $10 \mathrm{ng} / \mathrm{mL}$ TGF- $\beta 1$. H\&E staining of the pellets (A); alcian blue staining (B); immunohistochemical staining for detection of type II collagen (C) and type I collagen (D). There were no notable differences in histological and immunohistochemical examinations with pellets which have not been treated by TGF- $\beta 1$. Scale bar $100 \mu \mathrm{m}$.

the cells in the superficial layer. Metachromatic staining and morphology of the cells suggested that a cartilaginous matrix had been synthesized. To confirm these findings, immunohistochemical analysis for type II collagen was carried out using mono-specific antibody. Positive immunostained areas corresponded to the metachromatic stained areas and comprised the entire pellets on day 20 (Fig. 2K). Type I collagen was detected in all of the pellet groups, and its intensity increased towards the surface of the pellets opposite of the expression of type II collagen (Fig. 2D, H, L). There were not any notable differences on immunohistochemical examination between the pellets treated by TGF- $\beta 1$ in concentrations of 1 and $5 \mathrm{ng} / \mathrm{mL}$ (data not shown), pellets treated in concentrations of $10 \mathrm{ng} / \mathrm{mL}$ (Fig. 3), and pellets that were not treated (Fig. 2) during culturing of 20 days.

\section{In situ hybridization}

To verify results obtained from histological and immunohistochemical examination, in situ hybridization on the pellets cultured for 20 days was carried out. Type II collagen mRNA was strongly expressed in cells at the center of pellets and in the areas where pellets were densely organized (Fig. 4A). On the other hand, type I collagen mRNA was strongly expressed in the cells at the periphery of the pellets, and in less densely organized areas (Fig. 4B). Aggrecan mRNA was expressed throughout entire pellets with slightly more intensive expression at the centers (Fig. 4C). There were no notable differences in expression of mRNA between groups of pellets differing in concentrations of TGF$\beta 1$ (data not shown).

\section{Measurement of mRNA expression}

Total RNA was extracted from the MSC in pellet culture on day 1 and 20, and from MSC and chondrocytes cultured in monolayer manner for 20 days. There was no expression of chondrocyte-specific genes in pellets after one day of culturing or in the MSC from the monolayer culture (Fig. 5). Type II collagen and aggrecan mRNA expression were detected in pellets cultured for 20 days. In pellets that were not treated by TGF- $\beta 1$, type II collagen mRNA was 1.7 -fold higher compared to pellets cultured with TGF- $\beta 1$ (Fig. 6). TGF- $\beta 1$ did not have some influence on aggrecan mRNA expression in pellet-cultured MSC (Fig. 7). When type II collagen gene expression of MSC in pellet culture was compared to that of chondrocytes, the MSC exhibited 2.4-fold higher expression. Opposite of that, aggrecan mRNA expression in MSC from pellet culture was 3.1-fold lower than the expression level in the chondrocytes. Expression level of type I collagen mRNA of MSC in monolayer was 3.6-fold higher than that in pellet culture. TGF- $\beta 1$ did not have some remarkable influence on expression of type I collagen in pellet culture. During culturing in monolayer manner, chondrocytes showed a normal shift from collagen type II to collagen type I gene expression (Fig. 5), but still kept the chondrogenic phenotype [27,28,32].

\section{Discussion}

In the present study, we demonstrated that expanded bovine MSC undergo chondrogenesis under appropriate culture conditions in a serum-free chemically defined medium. Independent, spontaneous chondrogenesis of bovine MSC in
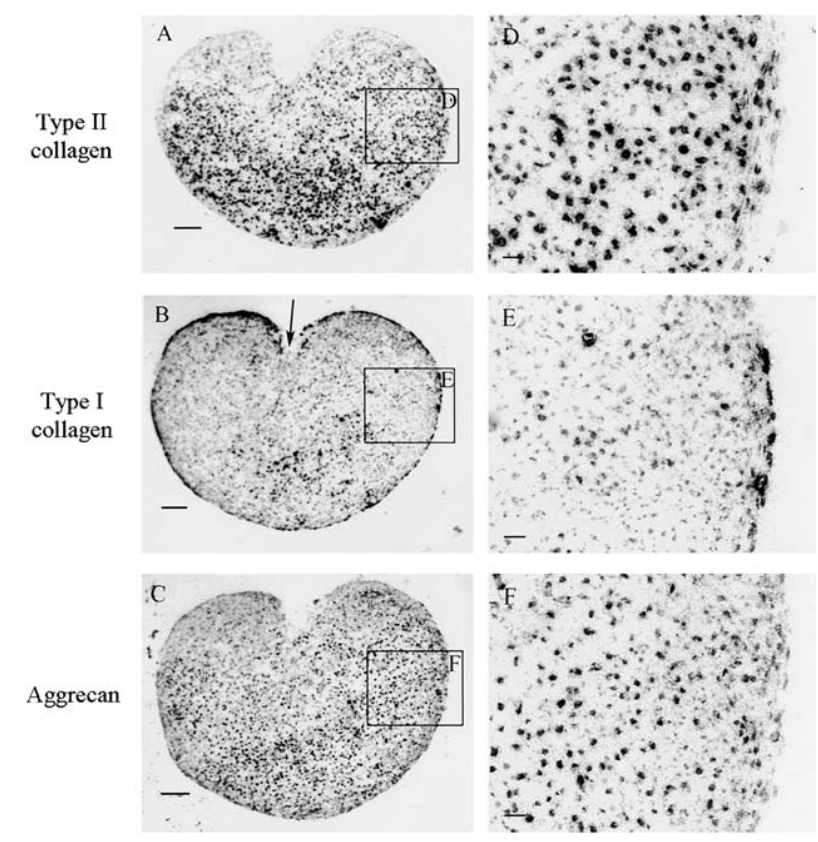

Figure 4. In situ hybridization of the pellet without treatment by TGF- $\beta 1$ on day 20 for detection of type II collagen (A, D), type I collagen $(\mathbf{B}, \mathbf{E})$, and aggrecan mRNA $(\mathbf{C}, \mathbf{F})$. Type I collagen mRNA was strongly expressed in the cells on the surface of the pellet or in less densely organized areas (black arrow). Opposite of that, type II collagen and aggrecan mRNAs were expressed in the deeper part of the pellets. Scale bar (A, B, C) $50 \mu \mathrm{m}$; scale bar (D, E, F) $200 \mu \mathrm{m}$. 


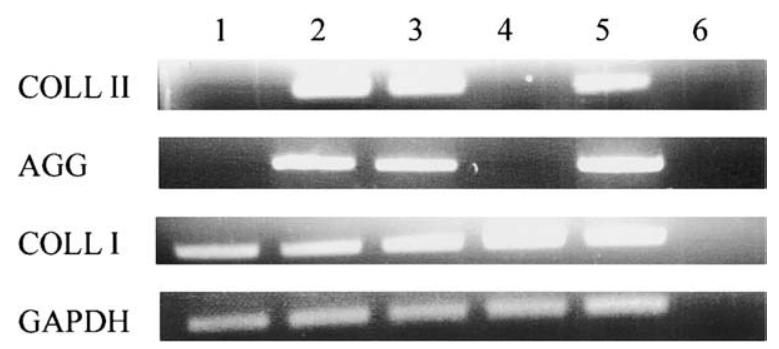

Figure 5. Electrophoresis of the PCR products from RT-PCR analysis of type II collagen (COLL II), aggrecan (AGG), type I collagen (COLL I), and GAPDH mRNA expression: (1) MSC in pellet culture on day 1; (2) MSC in pellet culture on day 20; (3) MSC in pellet culture on day 20 treated with $10 \mathrm{ng} / \mathrm{mL}$ TGF- $\beta 1$; (4) MSC in monolayer on day 20; (5) chondrocytes in monolayer culture on day 20; (6) negative control (without reverse transcriptase). Type II collagen and aggrecan were not detected in the MSC cultured in monolayer for 20 days and in pellet culture for 1 day.

pellet culture occurred without addition of any external bioactive stimulators, namely TGF- $\beta 1$, which was previously reported to be necessary [13-15,33]. The presence of metachromatic-staining matrix, the chondrocytic appearance of the cells, and detections of type II collagen and aggrecan mRNAs and proteins in the pellets showed that the tissue formed by these marrow-derived cells is cartilage.

Bovine MSC had spindle, bipolar to polygonal fibroblastic shape, and exhibited similar form to MSC isolated from other species $[1,8-16]$. On examination by phase contrast microscope, cell culture appeared to be homogeneous after the third or fourth changing of the medium, by the removal of nonadherent cells from hematopoietic lineage. Fluorescenceactivated cell sorting (FACS) analysis of the cells from the first passage showed homogeneous cell size population, negative on CD4 (data not shown). Morphology and the fact that cells were able to undergo adipogenic and osteogenic differentiation in monolayer culture (data not shown), as well as chondrogenic differentiation in pellet culture, were the reasons for classifying them as MSCs $[12,16]$.

Chondrogenesis was proven by the detection of sulfated GAG and strong immunoreactivity for type II collagen in

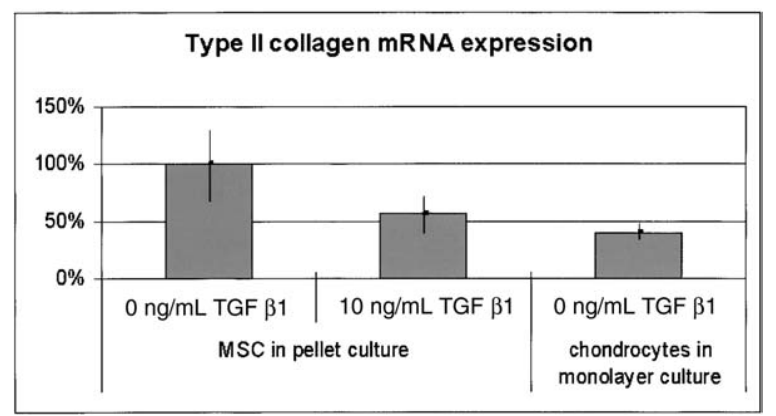

Figure 6. Quantitative analysis of type II collagen gene expression of MSC in pellet culture treated with 0 and $10 \mathrm{ng} / \mathrm{mL}$ TGF- $\beta 1$, and in chondrocytes cultured in monolayer manner for 20 days. The expression level was normalized for the level of GAPDH mRNA. Expression of type II collagen in pellet culture without treatment by TGF- $\beta 1$ was presented to be $100 \%$. Data were evaluated from 4 independent experiments and shown mean \pm SD.

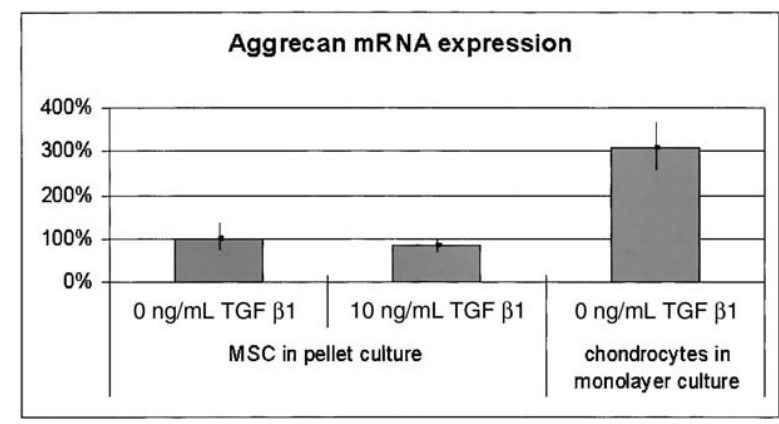

Figure 7. Quantitative analysis of aggrecan gene expression of MSC in pellet culture treated with 0 and $10 \mathrm{ng} / \mathrm{mL}$ TGF- $\beta 1$, and in chondrocytes cultured in monolayer manner for 20 days. The expression level was normalized for the level of GAPDH mRNA. Expression of aggrecan in pellet culture without treatment by TGF- $\beta 1$ was presented to be $100 \%$.

the center of the pellets after 7 days of culturing. The positive stained area for chondrocytic markers increased with culturing time, and almost whole pellets were positively stained after 20 days culturing. MSC from most of the species undergo chondrogenesis under specific circumstances to satisfy the following conditions: high cell density, which allows cell-to-cell interaction analogous to those occurring in precartilage mesenchymal condensation during limb development; and the action of bioactive factors that stimulate chondrogenesis (e.g., TGF- $\beta$, BMP, FGF, IGF-I, and dexamethasone) [15]. The condensed condition can be obtained by pellet culture systems [33], which were sufficient external stimulants for bovine MSC to undergo chondrogenesis. In our study for preparations of pellets, we used 4 times larger numbers of cells [29] compared to previous reports [33-36]. The reason was to obtain pellet volume as large as possible, so that the cells present in the central region would be under higher pressure. Also, large pellets provide a larger number of cells to have better conditions for cell-to-cell interactions. However, we found that spontaneous chondrogenesis of bovine MSC did not depend on the initiating cell number used for pellet preparation (data not shown). Previously Reyes et al. also used $1 \times 10^{6}$ cells for pellet preparation, but they had to treat human MSC by TGF- $\beta 1$ to induce chondrogenesis [29]. Present in situ hybridization clearly showed highest expression levels of type II collagen mRNA at the center region of the pellet where the cell density was higher, suggesting that condensed condition obtained by the pellet culture system is important for induction of chondrogenesis. Conversely, on the surface of the pellets, where the conditions look similar to monolayer culture, the cells expressed type I collagen and aggrecan, but no type II collagen (Fig. 4). In vitro monolayer cultivation of chondrocytes is accompanied by dedifferentiation with expression of collagen type I, which turns to redifferentiation of the same cells with an increase of collagen type II expression in threedimensional cultures $[37,38]$. The importance of the culture condition in chondrogenesis, being independent of bioactive stimulators, has also been reported in rabbit periosteal explants cultured in agarose gels [39]. 
There are several possible explanations concerning the self-induced chondrogenesis in bovine MSC. One of them is the species-specific character of stem cells. MSC have been isolated and characterized from almost all of the experimental animals and humans, and exhibited some speciesspecific characteristics in each. For example, in ovine [40] and feline [14] MSC, ALP activity could not be detected during osteogenic differentiation; however, increase of ALP activity is a typical osteogenic phenotype for human and rat MSC $[17,41]$. In cultures of embryonic chick limb bud cells and rabbit periosteal explants, TGF- $\beta 1$ induced the formation of cartilaginous tissue $[42,43]$, whereas rat periosteal cell in pellet culture failed to undergo chondrogenesis by the treatment of TGF- $\beta 1$ [44]. MSC derived from almost all species except rat [44] formed cartilage by the pellet culture in response to TGF- $\beta 1$ and dexamethasone. In other animals, spontaneous chondrogenic differentiation of stem cells was reported to be only sporadic. Fortier et al. reported spontaneous chondrogenesis of equine MSC cultured in monolayer manner in culture medium supplemented with $10 \%$ FBS [12]. However, chondrogenesis did not occur in serum-free medium, which could not eliminate the influence of bioactive stimulants present in the FBS.

The mechanism of chondrogenesis without any bioactive stimulants observed in bovine MSC remains unknown and is the subject of our ongoing research. Most likely, the condensed culture condition is the first stimulant for inducing further autocrine/paracrine cytokine secretion on a cellular level, which proceeds to complete differentiation to the chondrocytes. However, it is not yet reliable to discuss which cytokine, or what other factors may play a role.

TGF- $\beta 1$ treatment of bovine MSC in pellet culture decreased expression of type II collagen mRNA. The same effect of TGF- $\beta 1$ has been reported on freshly isolated chondrocytes cultured in monolayer culture [16]. The effects of TGF- $\beta 1$ on chondrocyte proliferation and synthesis of extracellular matrix proteoglycan and type II collagen is contextual and may be stimulatory or inhibitory, depending on the stage of cellular differentiation, growth condition, and the presence of other factors. TGF- $\beta 1$ reduced matrix protein expression and inhibited DNA synthesis in freshly isolated chondrocytes, but stimulated collagen type II and aggrecan expression in long-term cultured cells [45]. In monolayer culture, chondrocytes changed their form from the polygonal one recognized immediately after isolation to the fibroblastic one observed after one week of culturing. During these transformations of cell shape, type II TGF- $\beta$ receptors changed in size. Type II TGF- $\beta$ receptors predominantly expressed in cultured chondrocytes are approximately $15 \mathrm{kDa}$ smaller than those expressed in freshly isolated chondrocytes, and are postulated to be nonfunctional [45]. Long-term cultured chondrocytes have fibroblastic shapes similar to MSC expanded in monolayer for two passages, and both respond to stimulation with TGF- $\beta 1$ by expression of type II collagen mRNA (our unpublished data). MSC in pellet culture changed their shape from fibroblastic to polygonal, in which case TGF- $\beta 1$ actually had a suppressive effect on expression of type II collagen.

It has been previously reported that age of the donor had no relationship with the ability of the culture-expanded MSC to undergo chondrogenesis [46]. Some other stem cells with chondrogenic potential, derived from a different origin, such as human periosteum-derived cells from donors younger than 30 years, undergo focal chondrogenic differentiation in the first or second passage in monolayer culture $[34,47,48]$. De Bari looked for a possible explanation for losing potential for spontaneous chondrogenesis upon passaging in the cell selection, so that periosteum-derived cells responsible for the formation of chondrogenic nodules were overgrown by other cell subsets [34]. Physical and health conditions of the donors might have influence on the characteristics and potential of the stem cells. For example, human MSC isolated from patients with advanced osteoarthritis have reduced chondrogenic and adipogenic activities [46]. Considering these results, we should mention that bone marrow aspirates in our study were harvested from young animals ( 2 days to 6 months old), and could be one of the reasons for the observed high chondrogenic potential of the cells. In addition, we confirmed spontaneous chondrogenesis of bovine MSC isolated from adult donors (more than 4 years old), but comparing chondrogenic potentional of MSC harvested from young to that of adult animals was beyond the scope of our research.

In conclusion, we demonstrated that the species character must be considered in all experiments involving MSC. We have shown that the process of chondrogenic differentiation in bovine MSC appears to be different from other species, but further experimental work is necessary in order to be well understood. Finally, we made the first step in establishing a new animal experimental model for MSC research.

\section{References}

1. Haynesworth SE, Baber MA, Caplan AI. Cell surface antigens on human marrow-derived mesenchymal cells are detected by monoclonal antibodies. Bone. 1992;13:69-80.

2. Reynolds BA, Weiss S. Generation of neurons and astrocytes from isolated cells of the adult mammalian central nervous system. Science. 1992;255:1707-1710.

3. Gage FH. Mammalian neural stem cells. Science. 2000;287:1433-1438.

4. Tropepe V, Coles BL, Chiasson BJ, et al. Retinal stem cells in the adult mammalian eye. Science. 2000;287:2032-2036.

5. Jackson KA, Mi T, Goodell MA. Hematopoietic potential of stem cells isolated from murine skeletal muscle. Proc Natl Acad Sci U S A. 1999; 96:14482-14486.

6. Toma JG, Akhavan M, Fernandes KJ, et al. Isolation of multipotent adult stem cells from the dermis of mammalian skin. Nat Cell Biol. 2001;3:778-784.

7. Zuk PA, Zhu M, Ashjian P, et al. Human adipose tissue is a source of multipotent stem cells. Mol Biol Cell. 2002;13:4279-4295.

8. Dennis JE, Caplan AI. Porous ceramic vehicles for rat-marrow-derived (Rattus norvegicus) osteogenic cell delivery: effects of pre-treatment with fibronectin or laminin. J Oral Implantol. 1993;19:106-115. 
9. Wakitani S, Goto T, Pineda SJ, et al. Mesenchymal cell-based repair of large, full-thickness defects of articular cartilage. J Bone Joint Surg Am. 1994;76:579-592.

10. Kadiyala S, Young RG, Thiede MA, Bruder SP. Culture expanded canine mesenchymal stem cells possess osteochondrogenic potential in vivo and in vitro. Cell Transplant. 1997;6:125-134.

11. Jiang Y, Jahagirdar BN, Reinhardt RL, et al. Pluripotency of mesenchymal stem cells derived from adult marrow. Nature. 2002;418:41-49.

12. Fortier LA, Nixon AJ, Williams J, Cable CS. Isolation and chondrocytic differentiation of equine bone marrow-derived mesenchymal stem cells. Am J Vet Res. 1998;59:1182-1187.

13. Ringe J, Kaps C, Schmitt B, et al. Porcine mesenchymal stem cells. Induction of distinct mesenchymal cell lineages. Cell Tissue Res. 2002; 307:321-327.

14. Martin DR, Cox NR, Hathcock TL, Niemeyer GP, Baker HJ. Isolation and characterization of multipotential mesenchymal stem cells from feline bone marrow. Exp Hematol. 2002;30:879-886.

15. Mastrogiacomo M, Cancedda R, Quarto R. Effect of different growth factors on the chondrogenic potential of human bone marrow stromal cells. Osteoarthritis Cartilage. 2001;9(suppl A):S36-40.

16. Worster AA, Nixon AJ, Brower-Toland BD, Williams J. Effect of transforming growth factor $\beta 1$ on chondrogenic differentiation of cultured equine mesenchymal stem cells. Am J Vet Res. 2000;61:10031010 .

17. Jaiswal N, Haynesworth SE, Caplan AI, Bruder SP. Osteogenic differentiation of purified, culture-expanded human mesenchymal stem cells in vitro. J Cell Biochem. 1997;64:295-312.

18. Phinney DG, Kopen G, Isaacson RL, Prockop DJ. Plastic adherent stromal cells from the bone marrow of commonly used strains of inbred mice: variations in yield, growth, and differentiation. J Cell Biochem. 1999:72:570-585.

19. Phinney DG, Kopen G, Righter W, Webster S, Tremain N, Prockop DJ. Donor variation in the growth properties and osteogenic potential of human marrow stromal cells. J Cell Biochem. 1999;75:424-436.

20. Hung SC, Chen NJ, Hsieh SL, Li H, Ma HL, Lo WH. Isolation and characterization of size-sieved stem cells from human bone marrow. Stem Cells. 2002;20:249-258.

21. Sekiya I, Larson BL, Smith JR, Pochampally R, Cui JG, Prockop DJ. Expansion of human adult stem cells from bone marrow stroma: conditions that maximize the yields of early progenitors and evaluate their quality. Stem Cells. 2002;20:530-541.

22. Aerssens J, Boonen S, Lowet G, Dequeker J. Interspecies differences in bone composition, density, and quality: potential implications for in vivo bone research. Endocrinology. 1998;139:663-670.

23. Liu Y, Chen F, Liu W, et al. Repairing large porcine full-thickness defects of articular cartilage using autologous chondrocyte-engineered cartilage. Tissue Eng. 2002;8:709-721.

24. Kon E, Muraglia A, Corsi A, et al. Autologous bone marrow stromal cells loaded onto porous hydroxyapatite ceramic accelerate bone repair in critical-size defects of sheep long bones. J Biomed Mater Res. 2000; 49:328-337.

25. Worster AA, Brower-Toland BD, Fortier LA, Bent SJ, Williams J, Nixon AJ. Chondrocytic differentiation of mesenchymal stem cells sequentially exposed to transforming growth factor- $\beta 1$ in monolayer and insulin-like growth factor-I in a three-dimensional matrix. J Orthop Res. 2000;19:738-749.

26. Holzer G, Einhorn TA, Majeska RJ. Estrogen regulation of growth and alkaline phosphatase expression by cultured human bone marrow stromal cells. J Orthop Res. 2002;20:281-288.

27. Kim G, Okumura M, Bosnakovski D, et al. Effects of ascorbic acid on proliferation and biological properties of bovine chondrocytes in alginate beads. Jpn J Vet Res. 2003;51:83-94.

28. Hering TM, Kollar J, Huynh TD, Varelas JB, Sandell LJ. Modulation of extracellular matrix gene expression in bovine high-density chondrocyte cultures by ascorbic acid and enzymatic resuspension. Arch Biochem Biophys. 1994;314:90-98.
29. Reyes M, Lund T, Lenvik T, Aguiar D, Koodie L, Verfaillie CM. Purification and ex vivo expansion of postnatal human marrow mesodermal progenitor cells. Blood. 2001;98:2615-2625.

30. Mowa CN, Iwanaga T. Expression of estrogen receptor- $\alpha$ and $-\beta$ mRNAs in the male reproductive system of the rat as revealed by in situ hybridization. J Mol Endocrinol. 2001;26:165-174.

31. Digirolamo CM, Stokes D, Colter D, Phinney DG, Class R, Prockop DJ. Propagation and senescence of human marrow stromal cells in culture: a simple colony-forming assay identifies samples with the greatest potential to propagate and differentiate. Br J Haematol. 1999; 107:275-281.

32. Kolettas E, Buluwela L, Bayliss MT, Muir HI. Expression of cartilagespecific molecules is retained on long-term culture of human articular chondrocytes. J Cell Sci. 1995;108:1991-1999.

33. Johnstone B, Hering TM, Caplan AI, Goldberg VM, Yoo JU. In vitro chondrogenesis of bone marrow-derived mesenchymal progenitor cells. Exp Cell Res. 1998;238:265-272.

34. De Bari C, Dell' Accio F, Luyten FP. Human periosteum-derived cells maintain phenotypic stability and chondrogenic potential throughout expansion regardless of donor age. Arthritis Rheum. 2001;44:85-95.

35. Izumi T, Scully SP, Heydemann A, Bolander ME. Transforming growth factor $\beta 1$ stimulates type II collagen expression in cultured periosteumderived cells. J Bone Miner Res. 1992;7:115-121.

36. Murphy JM, Dixon K, Beck S, Fabian D, Feldman A, Barry F. Reduced chondrogenic and adipogenic activity of mesenchymal stem cells from patients with advanced osteoarthritis. Arthritis Rheum. 2002;46:704713.

37. Lemare F, Steimberg N, Le Griel C, Demignot S, Adolphe M. Dedifferentiated chondrocytes cultured in alginate beads: restoration of the differentiated phenotype and of the metabolic responses to interleukin- $1 \beta$. J Cell Physiol. 1998;176:303-313.

38. Schulze-Tanzil G, de Souza P, Villegas Castrejon H, et al. Redifferentiation of dedifferentiated human chondrocytes in high-density cultures. Cell Tissue Res. 2002;308:371-379.

39. O'Driscoll SW, Recklies AD, Poole AR. Chondrogenesis in periosteal explants. An organ culture model for in vitro study. J Bone Joint Surg Am. 1994;76:1042-1051.

40. Kon E, Muraglia A, Corsi A, et al. Autologous bone marrow stromal cells loaded onto porous hydroxyapatite ceramic accelerate bone repair in critical-size defects of sheep long bones. J Biomed Mater Res. 2000; 49:328-337.

41. Mizuno M, Fujisawa R, Kuboki Y. Type I collagen-induced osteoblastic differentiation of bone-marrow cells mediated by collagen- $\alpha 2 \beta 1$ integrin interaction. J Cell Physiol. 2000;184:207-213.

42. Roark EF, Greer K. Transforming growth factor - $\beta$ and bone morphogenetic protein-2 act by distinct mechanisms to promote chick limb cartilage differentiation in vitro. Dev Dyn. 1994;200:103-116.

43. Nishimura K, Solchaga LA, Caplan AI, Yoo JU, Goldberg VM, Johnstone B. Chondroprogenitor cells of synovial tissue. Arthritis Rheum. 1999;42:2631-2637.

44. Hanada K, Solchaga LA, Caplan AI, et al. BMP-2 induction and TGF$\beta 1$ modulation of rat periosteal cell chondrogenesis. J Cell Biochem. 2001;81:284-294.

45. Glansbeek HL, van der Kraan PM, Vitters EL, van den Berg WB. Correlation of the size of type II transforming growth factor $\beta$ (TGF- $\beta$ ) receptor with TGF- $\beta$ responses of isolated bovine articular chondrocytes. Ann Rheum Dis. 1993;52:812-816.

46. Yoo JU, Barthel TS, Nishimura K, et al. The chondrogenic potential of human bone-marrow-derived mesenchymal progenitor cells. J Bone Joint Surg Am. 1998;80:1745-1757.

47. Nakahara H, Bruder SP, Haynesworth SE, et al. Bone and cartilage formation in diffusion chambers by subcultured cells derived from the periosteum. Bone. 1990;11:181-188.

48. Nakata $\mathrm{K}$, Nakahara $\mathrm{H}$, Kimura T, et al. Collagen gene expression during chondrogenesis from chick periosteum-derived cells. FEBS Lett. 1992; 299:278-282. 